\title{
Correction to: Update on the EFFECTS study of fluoxetine for stroke recovery: a randomised controlled trial in Sweden
}

Erik Lundström ${ }^{1,2^{*}}$, Eva Isaksson ${ }^{2}$, Per Näsman ${ }^{3}$, Per Wester ${ }^{4,5}$, Björn Mårtensson ${ }^{6}$, Bo Norrving ${ }^{7}$, Håkan Wallén ${ }^{8}$, Jörgen Borg ${ }^{4}$, Martin Dennis ${ }^{9}$, Gillian Mead ${ }^{9}$, Graeme J. Hankey ${ }^{10}$, Maree L. Hackett ${ }^{11,12}$, Katharina S. Sunnerhagen ${ }^{13,14,15,16}$ and For the EFFECTS Trial Collaboration

\section{Correction to: Trials (2020) 21:233}

\section{https://doi.org/10.1186/s13063-020-4124-7}

Following publication of the original article [1], we were notified that one of the corresponding author's affiliations was omitted. Affiliation no. 2 is now added to for Prof. Erik Lundström.

\section{Author details}

'Department of Neuroscience, Neurology, Uppsala University, Akademiska, Sjukhuset, SE-751 85 Uppsala, Sweden. ${ }^{2}$ Department of Clinical Neuroscience, Neurology, Karolinska Institutet, Nobels väg 6, SE-171 76 Stockholm, Sweden. ${ }^{3}$ Centre for Safety Research, KTH Royal Institute of Technology, TR10 B, SE-100 44 Stockholm, Sweden. ${ }^{4}$ Department of Clinical Sciences, Danderyd Hospital, Karolinska Institutet, SE-182 88 Stockholm, Sweden. ${ }^{5}$ Department of Public Health \& Clinical Medicine, Umeå University, SE-901 87 Umeå, Sweden. ${ }^{6}$ Department of Clinical Neuroscience, Karolinska Institutet, SE-171 77 Stockholm, Sweden. 'Department of Clinical Sciences, Lund, Neurology, Skåne University Hospital, Lund University, SE-221 85 Lund, Sweden. ${ }^{8}$ Department of Clinical Sciences, Division of Cardiovascular Medicine, Danderyd Hospital, Karolinska Institutet, SE-182 88 Stockholm, Sweden. ${ }^{9}$ Royal Infirmary, University of Edinburgh, Edinburgh EH16 4SB, UK. ${ }^{10}$ Medical School, The University of Western Australia, Perth, Australia. ${ }^{11}$ The George Institute for Global Health, Faculty of Medicine, University of New South Wales Sydney, Sydney, Australia. ${ }^{12}$ The University of Central Lancashire, Preston, UK. ${ }^{13}$ Institute of Neuroscience and Physiology, The Sahlgrenska Academy, University of Gothenburg, Gothenburg, Sweden. ${ }^{14}$ Riga Stradins University, Riga, Latvia. ${ }^{15}$ Sunnaas Rehabilitation Hospital, Bjørnemy, Norway. ${ }^{16}$ Rehabilitation Medicine, Sahlgrenska University Hospital, Gothenburg, Sweden.
Published online: 07 May 2020

\section{Reference}

1. Lundström $E$, et al. Update on the EFFECTS study of fluoxetine for stroke recovery: a randomised controlled trial in Sweden. Trials. 2020;21:233. https://doi.org/10.1186/s13063-020-4124-7.

The original article can be found online at https://doi.org/10.1186/s13063020-4124-7.

* Correspondence: erik.lundstrom@neuro.uu.se

'Department of Neuroscience, Neurology, Uppsala University, Akademiska, Sjukhuset, SE-751 85 Uppsala, Sweden

${ }^{2}$ Department of Clinical Neuroscience, Neurology, Karolinska Institutet, Nobels väg 6, SE-171 76 Stockholm, Sweden

Full list of author information is available at the end of the article

(c) The Author(s). 2020 Open Access This article is licensed under a Creative Commons Attribution 4.0 International License, which permits use, sharing, adaptation, distribution and reproduction in any medium or format, as long as you give appropriate credit to the original author(s) and the source, provide a link to the Creative Commons licence, and indicate if changes were made. The images or other third party material in this article are included in the article's Creative Commons licence, unless indicated otherwise in a credit line to the material. If material is not included in the article's Creative Commons licence and your intended use is not permitted by statutory regulation or exceeds the permitted use, you will need to obtain permission directly from the copyright holder. To view a copy of this licence, visit http://creativecommons.org/licenses/by/4.0/. The Creative Commons Public Domain Dedication waiver (http://creativecommons.org/publicdomain/zero/1.0/) applies to the data made available in this article, unless otherwise stated in a credit line to the data. 